\title{
Combining Paternally and Maternally Inherited Mitochondrial DNA for Analysis of Population Structure in Mussels
}

Robert A. Krebs

Cleveland State University, r.krebs@csuohio.edu

Follow this and additional works at: https://engagedscholarship.csuohio.edu/scibges_facpub

Part of the Biology Commons, and the Genetics Commons

How does access to this work benefit you? Let us know!

\section{Publisher's Statement}

This is the accepted version of the following article: Krebs RA. 2004. Combining paternally and maternally inherited mitochondrial DNA for analysis of population structure in mussels. Mol Ecol 13(6):1701-5., which has been published in final form at http://onlinelibrary.wiley.com/doi/ 10.1111/j.1365-294X.2004.02133.x/abstract

\section{Recommended Citation}

Krebs RA. 2004. Combining paternally and maternally inherited mitochondrial DNA for analysis of population structure in mussels. Mol Ecol 13(6):1701-5.

This Article is brought to you for free and open access by the Biological, Geological, and Environmental Sciences Department at EngagedScholarship@CSU. It has been accepted for inclusion in Biological, Geological, and Environmental Faculty Publications by an authorized administrator of EngagedScholarship@CSU. For more information, please contact library.es@csuohio.edu. 


\title{
SHORT COMMUNICATION
}

\section{Combining paternally and maternally inherited mitochondrial DNA for analysis of population structure in mussels}

\author{
ROBERT A. KREBS
}

Department of Biological, Geological and Environmental Sciences, Cleveland State University, 2121 Euclid Avenue, Cleveland, Ohio 44115, USA

\begin{abstract}
Sequence divergence for a fragment of the 16S rRNA gene was compared to identify the advantages in using mitochondrial genes that descend separately through the female and male lineages to examine population structure. The test compared divergence among four local species of freshwater mussels (Unionidae) and was extended to multiple populations of one species, Pyganodon grandis. For the same gene, the male-inherited sequences diverged at a faster rate, producing longer branch lengths in the phylogenies. Of particular use were sequences extracted from $P$. grandis populations from the southern region of the Lake Erie watershed (Ohio, USA); five male-inherited haplotypes were found. Only one change was observed in the female-inherited form in this region. Therefore, more rapid evolution has occurred in the male form of the gene, and this form provided stronger evidence of geographical isolation among populations. A combination of analyses on haplotypes derived through males and females creates complementary opportunities to identify evolutionary relationships caused by drift and migration in mussels.
\end{abstract}

Keywords: conservation, genetics, Mollusca, population, Pyganodon, Unionidae

\section{Introduction}

Unionid mussels possess a male-inherited form of mitochondria as well as the standard female-inherited form (Hoeh et al. 1996). While some marine bivalves (i.e. Mytilus) also possess two mitochondrial forms (Ladoukakis \& Zouros 2001), the male-inherited form in unionids is restricted to gonadal tissue (Liu et al. 1996). This tissue-specific location of paternally derived mitochondria in freshwater mussels may increase the utility by which maternal and paternal forms can be used concurrently to assess population structure (Liu \& Mitton 1996). Liu et al. (1996) highlighted how variation in these genes may be particularly useful for the study of populations within species because the maleinherited DNA sequence may evolve faster than the form inherited through the female lineage.

This study tested the hypothesis that a male-derived mitochondrial DNA sequence (or male mitotype) evolves

Correspondence: R. A. Krebs. Fax: 216-687-6972; E-mail: r.krebs@csuohio.edu faster than a female-derived sequence (or female mitotype). The approach was to examine first whether branch lengths in a phylogeny of different unionid species are greater for the male mitotype of the 16S rRNA gene than for the homologous female mitotype and second, to show that intraspecific polymorphism is greater within the male mitotype than in the female mitotype. The male form is restricted to the testes, requiring identification of males. A corollary to the work was to simplify methods for sequencing the male mitotype as male gonadal tissue contains a mix of the mitochondrial forms. The female form in unionids, but not necessarily in marine mussels (Ladoukakis \& Zouros 2001), can be purified by using nongonadal tissue, for example from the mantle or the adductor muscles, of any individual.

The geographical system in which the sequence variation was explored was the small rivers of the Lake Erie watershed in northern Ohio, USA. These rivers probably existed as tributaries of the large Maumee River system prior to the last ice age, and as the western part of Lake Erie filled in, each of these tributaries became isolated rivers 
flowing north into the lake (Ortmann 1924). Today, genetic variation among populations from these rivers remains of special interest because zebra mussels have essentially eliminated unionid mussels from the lake proper (Nichols \& Amberg 1999; Strayer 1999), thereby removing any opportunity for gene flow between rivers.

\section{Materials and methods}

The genetic work focused on variation among several unionid species common to northern Ohio. Pyganodon grandis, Lasmigona costata, Lampsilis radiata luteola and Fusconaia flava were collected from the Cuyahoga and Rocky River watersheds. These individuals were used to obtain the maleand female-derived sequences of an approximately 500base fragment of the 16S rRNA gene in the mitochondria, from which the female-derived sequences had been previously determined for each species (Krebs et al. 2003; GenBank accession numbers AY238480-AY238491).

The number of males collected was $17 P$. grandis, three $L$. costata, one L. radiata luteola and one F. flava. The P. grandis males were obtained from the West Branch of the Cuyahoga River $(n=3)$, Tinkers Creek $(n=5)$, the Ohio Canal $(n=1)$, the Rocky River $(n=1)$, Findley Lake in the Black River watershed $(n=3)$, from Fish Creek, which is a tributary of the Maumee River $(n=2)$, and from the Grand River $(n=2)$. These two latter sources were specimens obtained from The Ohio State University Museum of Biological Diversity (catalogue no. 0226 for Fish Creek collected in 1985 , no. 59763, for the Grand River, Ashtabula County collected in 1968, and no. 59794 for the Grand River, Trumbull County, collected in 1971) and represent an important test of the feasibility of using museum specimens in future work. Shells and soft tissue of all collected material are stored in the Department of Biological, Geological and Environmental Sciences at Cleveland State University.

Initial amplification employed two universal primers 16Sar-5' (CGCCTGTTTAACAAAAACAT) and 16Sbr-3' (CCGGTTTGAACTCAGATCATGT) that were optimized for insect use (Palumbi 1997), and these primed the synthesis of approximately 500 base pairs (bp) of $16 \mathrm{~S}$ mitochondrial DNA in unionid mussels (Lydeard et al. 1996). These universal primers amplified both male-derived and femalederived forms of DNA. Therefore, amplified sequences were cloned into a pGEM T Easy Vector (Promega) system to sequence specifically only one DNA product, as Hoeh et al. (1996) successfully applied to separately sequence male and female forms of the Cytochrome C Oxidase gene.

The large difference between male and female sequences (Fig. 1) enabled the development of gender-specific primers. A specific forward primer was designed for use with the universal reverse primer to obtain replicate sequences for three of the species: 16S 5'-ATGGTCTTTTGTTACTATAA$3^{\prime}$ primed male-derived DNA in Pyganodon grandis, $16 \mathrm{~S}$ 5'-

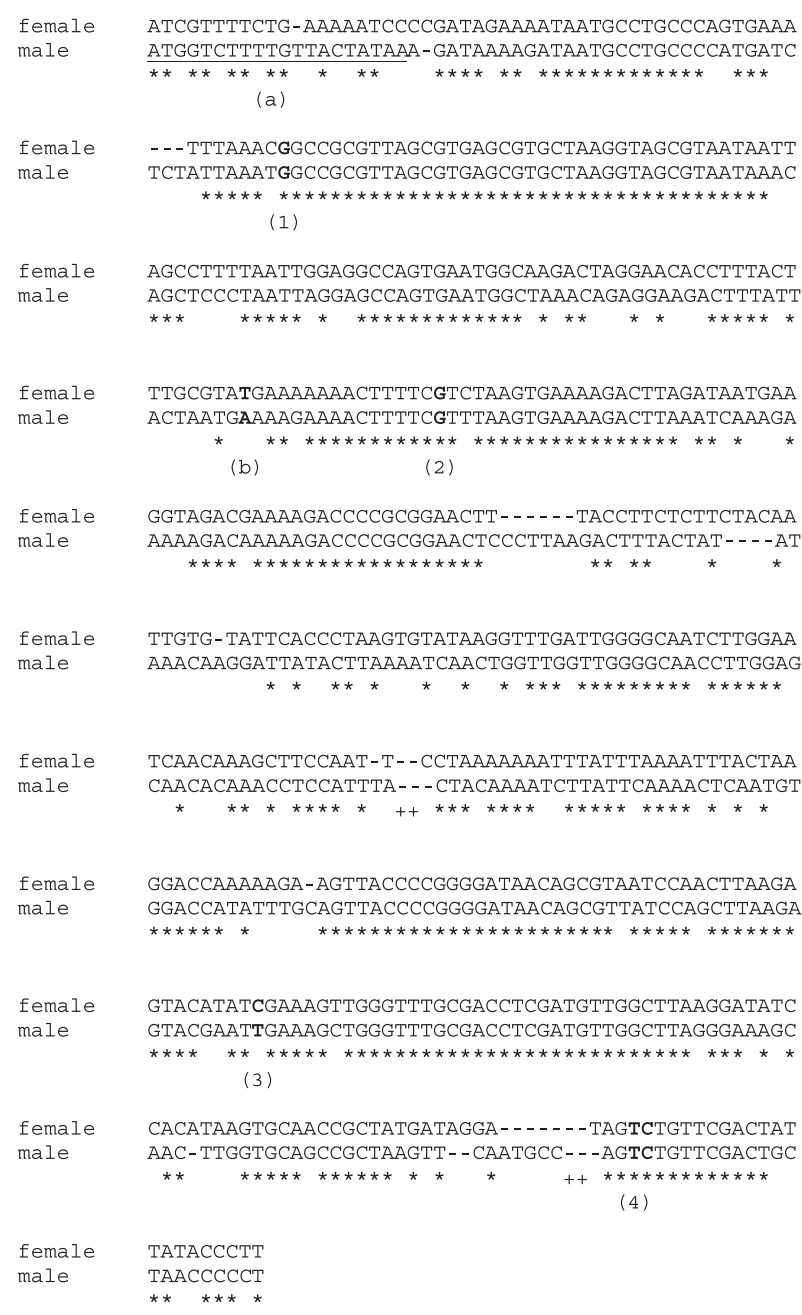

Fig. 1 A comparison of the $500 \mathrm{bp}$ at the $5^{\prime}$ end of the $16 \mathrm{~S}$ rRNA gene that was inherited through the female and male lineages of the same Pyganodon grandis individual. An asterisk indicates similar sites $(345 / 508)$, and + indicates shared indels within the Unionidae. Several features of the sequence are indicated (a) the male-specific primer sequence, (b) site of the one polymorphism in the female mitotype, and sites for four changes that produced the different male mitotypes: (1) a G-C transversion; (2) a G-A transition; (3) a T-C transition; and (4) an insertion of one C.

CGTCTTTTGCTATTATTAC-3' primed the same region for Lasmigona costata, and 16S 5'-CGTCTTTTGTTAACCTAATC-3' primed this region in Fusconaia flava. Each genderspecific primer lies at the very beginning of the sequence primed by 16 Sar-5' (Fig. 1), which therefore gave a similarly sized 16S rRNA gene sequence for male-derived DNA, as did the universal primers for the female mitotype. The male-specific primers successfully amplified the complete sequence in these four museum specimens, but an internal primer was required to amplify a 200-bp section of the female-derived form that included the known polymorphism. The 3' half was not successfully sequenced for these older female-inherited sequences. 
One limitation to using a male-specific gene is the difficulty of identifying males at the time of specimen collection. Shell characteristics of most unionids are monomorphic (Clarke 1981). Presence of a marsupium, in which females brood eggs, enabled obvious females to be eliminated from the study. With $P$. grandis, almost all individuals that lacked a marsupium were identified genetically as male.

After amplification, primer sequences were removed by a polyethylene glycol density centrifugation procedure (Krebs et al. 2003). The early samples were delivered to Cleveland Genomics for sequencing and later samples were sent to the Cleveland State University sequencing facility. All samples were sequenced in both directions.

All mitochondrial 16S rRNA sequences were entered into CLUSTALV, a package of multiple alignment programs. DNA transversions were (by program default) weighed more heavily than were transitions. The phylogenetic relationship among sequences was inferred using the DNA parsimony algorithm in PAUP version 10.0 (Swofford 2002). For the specific protocol, change from an occupied site to a deletion was counted as one change; reversion from a deletion to an occupied site was also counted as one change. Analyses included male- and female-derived sequences for four unionid species, and used the female-derived sequence for Quadrula quadrula as an outgroup. The genus Quadrula is described, together with Fusconaia, in the subfamily Ambleminae (Davis 1984), and therefore may be more closely related to this species than the others. However, analysis of the $16 \mathrm{~S}$ rRNA gene suggests that these genera separate at the base of this lineage and may be no closer than either is to the Lampsilinae (Lydeard et al. 1996), another subfamily. However, members of Quadrula, Fusconaia and Lampsilis remain a little more closely related than these groups are to the Anodontinae, which contains Pyganodon and Lasmigona, but DNA divergence among all four groups is as large as can be obtained within the Unionidae. A bootstrap analysis was run based on 1000 trees using a random order of sequence entry.

Haplotypes were analysed based on the rivers from which they were obtained to estimate the minimum number of mutational events necessary to explain the observed diversity for each mitochondrial form. These estimates assumed that geographically diverse haplotypes predated isolation of the rivers.

\section{Results}

From DNA extractions of the same individual, female- and male-derived sequence of the 16S rRNA gene in Pyganodon grandis possessed only $68 \%$ similarity (Fig. 1). The sequences for each form of the mitochondria that came from different species were much more similar and therefore the male form segregated completely from the female form in a cladistic analysis (Fig. 2, GenBank accession numbers AY498700-

\section{Phylogeny}

\section{Sequence diversity $\%$}

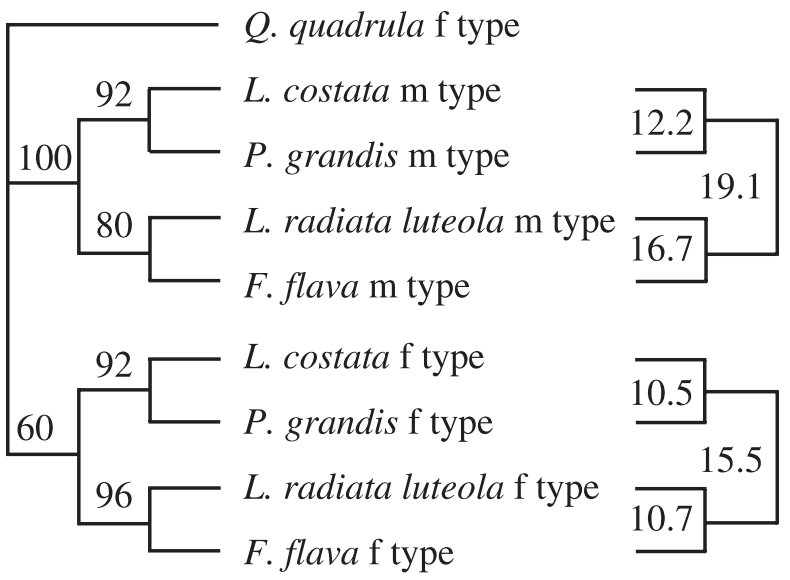

Fig. 2 Cladogram of the male (m type) and female (f type) forms of the mitochondrial 16S rRNA sequence based on a bootstrap analysis from PAUP v10. The female mitochondrial form of Quadrula quadrula was used as an outgroup. To the right, per cent sequence divergence is listed comparing Pyganodon grandis to Lasmigona costata, and Lampsilis radiata luteola to Fusconaia flava, and also comparing members of each clade for male and female forms of the sequence.

AY498703). The bootstrap value for the independence of the male lineage from the female lineage was $100 \%$, and the species phylogenies were identical.

However, the male-derived mitochondrial sequence varied more among species than did the female-derived sequences (Fig. 2). For all of the possible pairwise comparisons among the species, variation in the male-derived sequences exceeded that of the females in each case $(P<$ 0.05 , sign test), with a rate of change in males $16-36 \%$ faster than that for females (the average was $21 \%$ across all pairwise comparisons).

To address the utilization of polymorphism within species, sequences were compared for 17 male-inherited sequences and 23 female-inherited sequences of $P$. grandis across northern Ohio rivers (Fig. 3). While only a single sequence variant was found for female mitotypes, four base positions varied in males. Two variations were transitions, one was a transversion and one an indel (gene positions are marked in Fig. 1). These four variations produced five different haplotypes, and they required a minimum of five separate mutational events to produce the present pattern of diversity. In a smaller sample of three Lasmigona costata, all male sequences were identical.

\section{Discussion}

The male-derived and female-derived mitotypes gave the same gene phylogeny among the four unionid species 


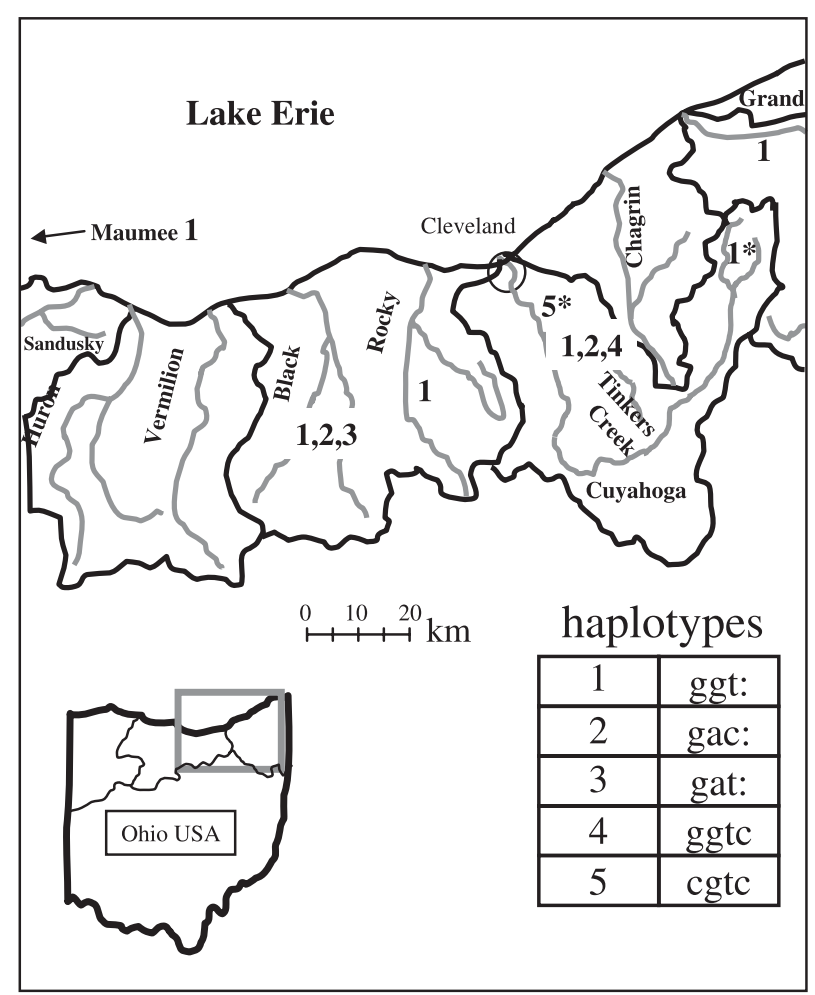

Fig. 3 The distribution of male and female-inherited haplotypes of the $16 \mathrm{~S}$ rRNA gene in Pyganodon grandis from the Ohio Lake Erie watershed. Male variants are indicated by number while the single female variant is identified by an asterisk following the male identifier.

compared, and this phylogeny agreed with earlier published results on the Unionidae using the 16S rRNA gene (Lydeard et al. 1996). While Liu et al. (1996) first proposed that male and female mitochondrial sequences in unionid mussels differ and that the male-inherited form may evolve faster, Hoeh et al. $(1996,2002)$ identified that variation between these forms is the result of divergence at least 200 million years ago. This deep ancestry enabled a test of evolutionary rate variation, and the estimate of the $21 \%$ faster rate in malederived rRNA genes should be robust across evolutionary time.

A critical outcome for ecological study is the advantage of applying male-specific gene techniques to population analyses. Even in a data set limited by the collection restrictions imposed on protected species such as unionid mussels, the male-inherited form provided clear evidence of diversification beyond that possible with the femaleinherited form alone. Neighbouring watersheds, especially the Black River and the Cuyahoga River, each possessed haplotypes not found elsewhere. A common history among these rivers is also indicated, as the predominant form of both the female and male mitochondria occurs in all five rivers from which samples were collected. Perhaps within the putatively large ancestral population, the female form may have been either invariant or have possessed very low levels of variation. Only the Cuyahoga River watershed samples included a different haplotype of the female form (five of six individuals), while a tributary, Tinkers Creek, contained only the ancestral type (Krebs et al. 2003).

Analysis of community aggregations supports the genetic analyses. The unionid fauna of Tinkers Creek resembles past rather than present assemblages observed for the Cuyahoga River, suggesting an historic separation (Tevesz et al. 2002). No mussels occur in the lower 1-2 miles (1.6$3.2 \mathrm{~km}$ ) of that tributary (Krebs et al. 2002; Smith et al. 2002). Therefore, like the Lake Erie tributaries, migration probably has little effect on population structure. The only evidence of gene flow between any of the streams studied here came from one Ohio Canal variant (haplotype 5) that is more similar to a derived male haplotype from Tinkers Creek (haplotype 4). The Ohio Canal, which is maintained as part of the Cuyahoga River National Park, receives its water from Tinkers Creek.

Thus, the combination of results from female-inherited and male-inherited forms of the mitochondria provide complementary support for the isolation of mussels among the rivers of northern Ohio. Most of these rivers are small, and mussel populations tend not to be numerous. As a consequence, genetic variation within rivers appears low, even for Pyganodon grandis, which is one of the most common species in Ohio and a species that utilizes large numbers of fish hosts (Watters 1995). While this species generally inhabits the middle and upper regions of these small rivers rather than the river mouths, it can be found throughout most rivers in the Lake Erie watershed (e.g. Metcalfe-Smith et al. 1998, 2000). Therefore, $P$. grandis can be predicted to show higher rates of gene flow than most other mussel species in this region, and yet, this small genetic study utilizing both male- and female-inherited forms of mitochondria successfully identified isolation within and between neighbouring watersheds.

Finally, as a technical note, most cloned fragments after amplifying the 16S rRNA gene from gonadal DNA contained the male-derived sequence. That outcome suggests that applying male mitotypes to phylogeny can be made routine. Also, for rRNA genes, only a single initial sequence is needed to create gender-specific primers as the stem and loop structure of these RNAs leads to both conserved and variable regions in males and females (Palumbi 1997). Amplifying male mitotypes from the universal primer was successful in this study. However, male-specific primers were used to confirm all the results presented here.

\section{Acknowledgements}

We thank the administrators of the Cuyahoga Valley National Park and the Ohio Division of Natural Resources for permission to 
collect mussels (Federal permit no. CUVA - 00-004; State Permit no. 652), and The Ohio State University, Museum of Biological Diversity for additional material. Several students at CSU, Louie Rundo, Bryan Child, Henk Markgraaff and Chuck Laszlo, assisted with data collection. The work was supported by an NSF small grant for exploratory research (DEB-0002305) and by a fellowship from the Program for Excellence in Risk Analysis in the Center for Environmental Science, Technology and Policy, CSU.

\section{References}

Clarke AH (1981) The Freshwater Molluscs of Canada. National Museums of Canada: Ottawa.

Davis GM (1984) Genetic relationships among some North American Unionidae (Bivalvia): sibling species, convergence and cladistic relationships. Malacologia, 25, 629-648.

Hoeh WR, Stewart DT, Sutherland BW, Zouros E (1996) Multiple origins of gender-associated mitochondrial DNA lineages in bivalves (Mollusca: Bivalvia). Evolution, 50, 2276-2286.

Hoeh WR, Stewart DT, Guttman SI (2002) High fidelity of mitochondrial genome transmission under the double uniparental mode of inheritance in freshwater mussels (Bivalvia: Unionoidea). Evolution, 56, 2252-2261.

Krebs RA, Griffith HM, Tevesz MJS (2002) A study of the Unionidae of Tinkers Creek Ohio. Kirtlandia, 53, 19-25.

Krebs RA, Vlasceanu RN, Tevesz MJS (2003) An analysis of diversity in freshwater mussels (Bivalvia: Unionidae) of the Cuyahoga and Rocky River watersheds (Ohio, USA) based on the 16S rRNA gene. Journal of Great Lakes Research, 29, 307-316.

Ladoukakis ED, Zouros E (2001) Direct evidence for homologous recombination in mussel (Mytilus galloprovincialis) mitochondrial DNA. Molecular Biology and Evolution, 18, 1168-1175.

Liu H, Mitton JB (1996) Tissue-specific maternal and paternal mitochondrial DNA in the freshwater mussel, Anodonta grandis grandis. Journal of Molluscan Studies, 62, 393-394.

Liu H, Mitton JB, Wu S (1996) Paternal mitochondrial DNA differentiation far exceeds maternal mitochondrial DNA and allozyme differentiation in the freshwater mussel, Anodonta grandis grandis. Evolution, 50, 952-957.

Lydeard C, Mulvey M, Davis G (1996) Molecular systematics and evolution of reproductive traits of North American freshwater unionacean mussels (Mollusca: Bivalvia) as inferred from $16 \mathrm{~S}$ rRNA gene sequences. Philosophical Transactions of the Royal Society, London B, 351, 1593-1603.

Metcalfe-Smith JL, Staton SK, Mackie GL, Lane NM (1998) Changes in the biodiversity of freshwater mussels in the Canadian waters of the lower Great Lakes drainage basin over the past 140 years. Journal of Great Lakes Research, 24, 845-858.

Metcalfe-Smith JL, Mackie GL, Di Maio J, Staton SK (2000) Changes over time in the diversity and distribution of freshwater mussels (Unionidae) in the Grand River, southwestern Ontario. Journal of Great Lakes Research, 26, 445-459.

Nichols SJ, Amberg J (1999) Co-existence of zebra mussels and freshwater unionids: population dynamics of Leptodea fragilis in a coastal wetland infested with zebra mussels. Canadian Journal of Zoology, 77, 423-432.

Ortmann AE (1924) Distributional features of Naiades in tributaries of Lake Erie. The American Midland Naturalist, 9, 101-117.

Palumbi SR (1997) Nucleic acids II: The polymerase chain reaction. In: Molecular Systematics, 2nd edn (eds Hillis DM, Moritz C, Mable BK), pp. 205-247. Sinauer, Washington DC.

Smith DC, Gates MA, Krebs RA, Tevesz MJS (2002) A survey of freshwater mussels (Unionidae) and other molluscs in the Cuyahoga Valley National Park. Ohio Biological Survey, Miscellaneous Contribution, 8, iv-31p.

Strayer DL (1999) Effects of alien species on freshwater molluscs in North America. Journal of the North American Benthological Society, 18, 74-98.

Swofford DL (2002) PAUP*. Phylogenetic Analysis Using Parsimony (*and Other Methods), Version 4. Sinauer Associates, Sunderland, MA.

Tevesz MJS, Rundo L, Krebs RA, Redman BG, DuFresne AS (2002) Changes in the freshwater mussel (Bivalvia: Unionidae) fauna of the Cuyahoga River, Ohio, since late prehistory. Kirtlandia, 53, 13-18.

Watters GT (1995) A Guide to the Freshwater Mussels of Ohio, 3rd edn. The Ohio Division of Wildlife: Columbus, $\mathrm{OH}$.

Robert Krebs studies how habitat disturbance impacts diversity in mussels of the Lake Erie watershed. Other research includes physiological consequences of environmental stress in Drosophila. 